\title{
Multisensory integration in action control
}

\author{
Christine Sutter ${ }^{1 *}$, Knut Drewing ${ }^{2}$ and Jochen Müsseler ${ }^{1}$ \\ 1 Department of Work and Cognitive Psychology, RWTH Aachen University, Aachen, Germany \\ 2 Department for Experimental Psychology, Institute for Psychology, Justus-Liebig University, Giessen, Germany \\ *Correspondence: christine.sutter@psych.rwth-aachen.de
}

Edited and reviewed by:

Bernhard Hommel, Leiden University, Netherlands

Keywords: human information processing, perception, tool use, recalibration, reference frame, vision, haptic, acoustics

The integration of multisensory information is an essential mechanism in perception and action control. Research in multisensory integration is concerned with how the information from the different sensory modalities, such as the senses of vision, hearing, smell, taste, touch, and proprioception, are integrated to a coherent representation of objects (for an overview, see e.g., Calvert et al., 2004). The combination of information from the different senses is central for action control. For instance, when you grasp for a rubber duck, you can see its size, feel its compliance and hear the sound it produces. Moreover, identical physical properties of an object can be provided by different senses. You can both see and feel the size of the rubber duck. Even when you grasp for the rubber duck with a tool (e.g., with tongs), the information from the proximal hand, from the effective part of the distal tool and from the eyes are integrated in a manner to act successfully (for limitations of this integration see Sutter et al., 2013).

Over the recent decade a surge of interest in multisensory integration and action control has been witnessed, especially in connection with the idea of a statistically optimized integration of multiple sensory sources. The human information processing system is assumed to adjust moment-by-moment the relative contribution of each sense's estimate to a multisensory task. The sense's contribution depends on its variance, so that the total variance of the multisensory estimate is lower than that for each sense alone. Accordingly, the validity of a statistically optimized multisensory integration has been demonstrated by extensive empirical research (e.g., Ernst and Banks, 2002; Alais and Burr, 2004; Reuschel et al., 2010), also in applied setting such as tool-use (e.g., Takahashi et al., 2009; in the present research topic: Takahashi and Watt, 2014).

For this perspective to mature it will be helpful to delve deeper into the multisensory information processing mechanisms and their neural correlates, asking about the range and constraints of these mechanisms, about its localization and involved networks. The contributions to the present research topic range from how information from different senses and action control are linked and modulated by object affordances (Garrido-Vásquez and Schubö, 2014), by task-irrelevant information (Juravle et al., 2013; Wendker et al., 2014; for a review see Wesslein et al., 2014), by temporal and spatial coupling within and between senses (Cameron et al., 2014; Mueller and Fiehler, 2014; Rieger et al., 2014; Sugano et al., 2014) to childhood development of multisensory mechanisms (Jovanovic and Drewing, 2014).

Correspondences between the information from different senses play an important role for multisensory integration.
Integration does, for instance, not take place when vision and touch are spatially separated (e.g., Gepshtein et al., 2005). However, cognitive approaches on action effect control assume that information from different senses is still coded and represented within the same cognitive domain, when the information concerns the same action (e.g., Müsseler, 1999; Hommel et al., 2001). The present research topic also addresses the corresponding issue of modality-specific action control (Boutin et al., 2013; Grunwald et al., 2014).

Overall, the present research topic broadens our view on how multisensory mechanisms add to action control. We thank all authors and all reviewers for their valuable contributions.

\section{ACKNOWLEDGMENT}

This research was supported to by a grant from the Deutsche Forschungsgemeinschaft (DFG, German Research Foundation) to Christine Sutter and Jochen Müsseler (DFG MU 1298/10).

\section{REFERENCES}

Alais, D., and Burr, D. (2004). The ventriloquist effect results from near-optimal bimodal integration. Curr. Biol. 14, 257-262. doi: 10.1016/j.cub.2004.01.029

Boutin, A., Massen, C., and Heuer, H. (2013). Modality-specific organization in the representation of sensorimotor sequences. Front. Psychol. 4:937. doi: 10.3389/fpsyg.2013.00937

Calvert, G. A., Spence, C., and Stein, B. E. (2004). The Handbook of Multisensory Processes. Cambridge, MA: The MIT Press.

Cameron, B. D., de la Malla, C., and López-Moliner, J. (2014). The role of differential delays in integrating transient visual and proprioceptive information. Front. Psychol. 5:50. doi: 10.3389/fpsyg.2014.00050

Ernst, M. O., and Banks, M. S. (2002). Humans integrate visual and haptic information in a statistically optimal fashion. Nature 415, 429-433. doi: $10.1038 / 415429$ a

Garrido-Vásquez, P., and Schubö, A. (2014). Modulation of visual attention by object affordance. Front. Psychol. 5:59. doi: 10.3389/fpsyg.2014.00059

Gepshtein, S., Burge, J., Ernst, M. O., and Banks, M. S. (2005). The combination of vision and touch depends on spatial proximity. J. Vis. 5, 1013-1023. doi: $10.1167 / 5.11 .7$

Grunwald, M., Muniyandi, M., Kim, H., Kim, J., Krause, F., Mueller, S., et al. (2014) Human haptic perception is interrupted by explorative stops of milliseconds. Front. Psychol. 5:292. doi: 10.3389/fpsyg.2014.00292

Hommel, B., Müsseler, J., Aschersleben, G., and Prinz, W. (2001). The theory of event coding (TEC): a framework for perception and action. Behav. Brain Sci. 24, 869-937. doi: 10.1017/S0140525X01000103

Jovanovic, B., and Drewing, K. (2014). The influence of intersensory discrepancy on visuo-haptic integration is similar in 6-year-old children and adults. Front. Psychol. 5:57. doi: 10.3389/fpsyg.2014.00057

Juravle, G., McGlone, F., and Spence, C. (2013). Context-dependent changes in tactile perception during movement execution. Front. Psychol. 4:913. doi: 10.3389/fpsyg.2013.00913

Mueller, S., and Fiehler, K. (2014). Gaze-dependent spatial updating of tactile targets in a localization task. Front. Psychol. 5:66. doi: 10.3389/fpsyg.2014.00066 
Müsseler, J. (1999). How independent from action control is perception? An eventcoding account for more equally-ranked crosstalks. Adv. Psychol. 129, 121-147. doi: 10.1016/S0166-4115(99)80014-4

Reuschel, J., Drewing, K., Henriques, D. Y. P., Rösler, F., and Fiehler, K. (2010) Optimal integration of visual and proprioceptive movement information along angular trajectories. Exp. Brain Res. 201, 853-862. doi: 10.1007/s00221-009. 2099-4

Rieger, M., Dietrich, S., and Prinz, W. (2014). Effects of angular gain transformations between movement and visual feedback on coordination performance in unimanual circling. Front. Psychol. 5:152. doi: 10.3389/fpsyg.2014. 00152

Sugano, Y., Keetels, M., and Vroomen, J. (2014). Concurrent sensorimotor temporal recalibration to different lags for the left and right hand. Front. Psychol. 5:140. doi: 10.3389/fpsyg.2014.00140

Sutter, C., Sülzenbrück, S., Rieger, M., and Müsseler, J. (2013). Limitations of distal effect anticipation when using tools. New Ideas Psychol. 31, 247-257. doi: 10.1016/j.newideapsych.2012.12.001

Takahashi, C., Diedrichsen, J., and Watt, S. J. (2009). Integration of vision and haptics during tool use. J. Vis. 9, 3.1-3.13. doi: 10.1167/9.6.3

Takahashi, C., and Watt, S. J. (2014). Visual-haptic integration with pliers and tongs: signal weights take account of changes in haptic sensitivity caused by different tools. Front. Psychol. 5:109. doi: 10.3389/fpsyg.2014.00109
Wendker, N., Sack, O. S., and Sutter, C. (2014). Visual target distance, but not visual cursor path length produces shifts in motor behavior. Front. Psychol. 5:225. doi: 10.3389/fpsyg.2014.00225

Wesslein, A.-K., Spence, C., and Frings, C. (2014). Vision affects tactile target and distractor processing even when space is task-irrelevant. Front. Psychol. 5:84 doi: 10.3389/fpsyg.2014.00084

Conflict of Interest Statement: The authors declare that the research was conducted in the absence of any commercial or financial relationships that could be construed as a potential conflict of interest.

Received: 16 May 2014; accepted: 16 May 2014; published online: 10 June 2014 Citation: Sutter C, Drewing K and Müsseler J (2014) Multisensory integration in action control. Front. Psychol. 5:544. doi: 10.3389/fpsyg.2014.00544

This article was submitted to Cognition, a section of the journal Frontiers in Psychology.

Copyright (c) 2014 Sutter, Drewing and Müsseler. This is an open-access article distributed under the terms of the Creative Commons Attribution License (CC BY). The use, distribution or reproduction in other forums is permitted, provided the original author(s) or licensor are credited and that the original publication in this journal is cited, in accordance with accepted academic practice. No use, distribution or reproduction is permitted which does not comply with these terms. 